\title{
Medical Image of the Week: Disseminated Coccidioidomycosis
}

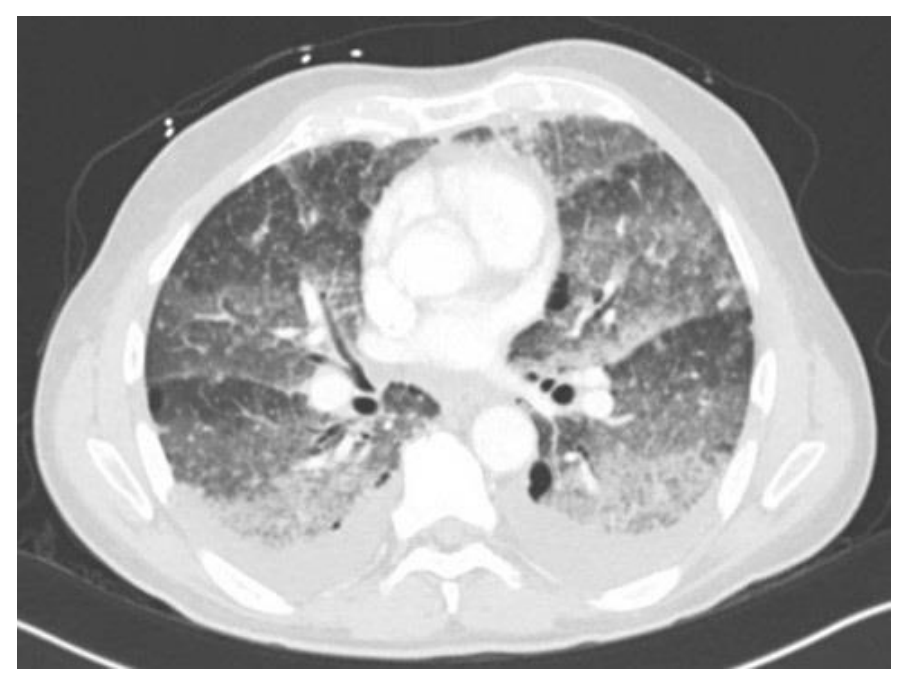

Figure 1. Thoracic CT with diffuse bilateral ground glass opacities with extensive nodularity. Though present throughout all lobes, it is worse in the upper lobes.

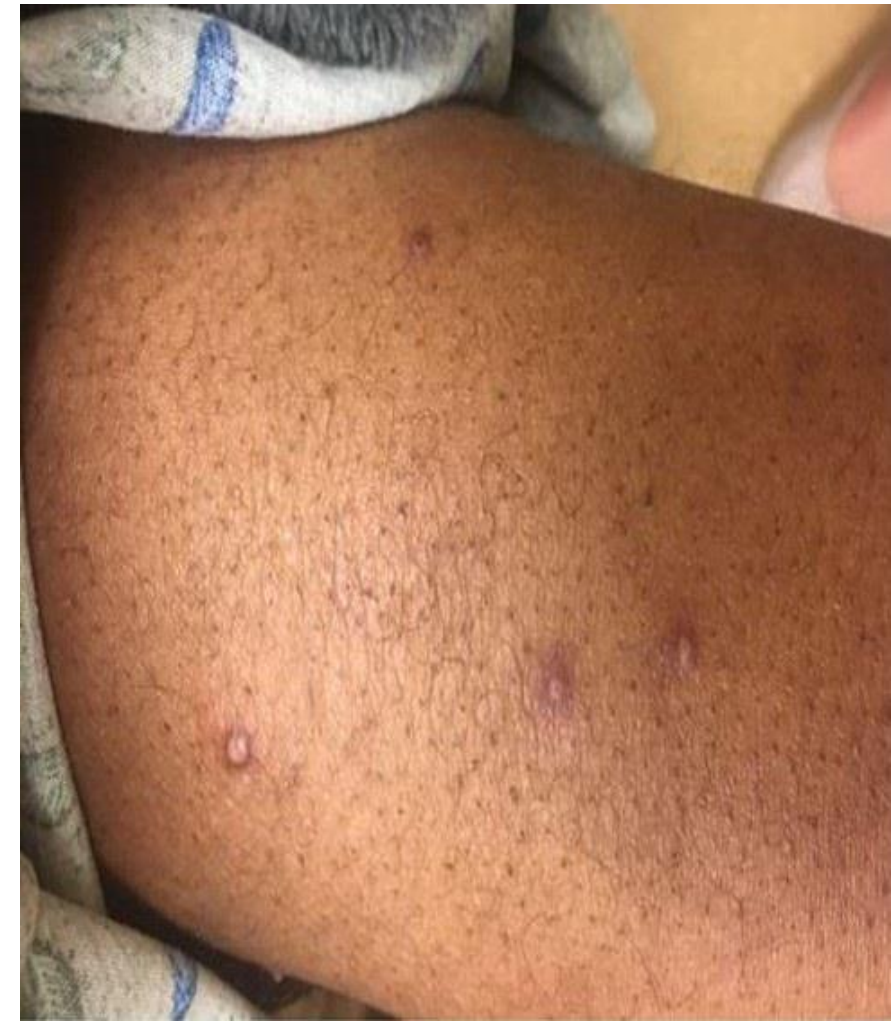

Figure 2. Scattered papular lesions with biopsy positive for coccidioidomycosis spherules. 
A 67-year-old African American man with no significant past medical history presented with shortness of breath and flu-like symptoms. On exam, he was noted to be profoundly hypoxemic with imaging showing diffuse thoracic changes (Figure 1) and a diffuse papular rash (Figure 2). Initial workup included coccidioidomycosis serologies which returned positive with a titer of 1:128.

While exposure to coccidioidomycosis is very common in southern Arizona, dissemination is a rare occurrence. The incidence is estimated between 0.2 and 4.7 percent. Patients at highest risk include those that are immunosuppressed or that are of African or Filipino ancestry. Common extra-pulmonary sites include skin or subcutaneous tissue, meninges of brain or spinal cord, and bones. Even rarer sites include the eyes, liver, prostate, mediastinum, and kidneys. Treatment is usually the same as with pulmonary infection which is an azole agent. However, if the patient's symptoms are severe or if the lesions involve the spine, amphotericin is recommended instead. Steroid use is controversial but may be beneficial in severe cases.

Unfortunately, our patient did not respond to the combination of fluconazole plus amphotericin and succumbed to his severe disease.

Tiffany Ynosencio, MD

Division of Pulmonary, Allergy, Critical Care and Sleep

Banner-University Medical Center

Tucson, AZ USA

\section{References}

1. Crum NF, Lederman ER, Stafford CM, Parrish JS, Wallace MR.

Coccidioidomycosis: a descriptive survey of a reemerging disease. Clinical characteristics and current controversies. Medicine (Baltimore). 2004 May;83(3):149-75.[CrossRef] [PubMed]

2. Adam RD, Elliott SP, Taljanovic MS. The spectrum and presentation of disseminated coccidioidomycosis. Am J Med. 2009 Aug;122(8):770-7. [CrossRef] [PubMed]

3. Galgiani JN. Manifestations and treatment of extrapulmonary coccidioidomycosis. UpToDate Jan 02, 2017. Available at:

http://www.uptodate.com/contents/manifestations-and-treatment-of-extrapulmonarycoccidioidomycosis (requires subscription). 